\title{
Study on Thermal Performances of a Small Loop Heat Pipe*
}

\author{
Hosei NAGANO $^{* *}$, Hiroki NAGAI ${ }^{* * *}$, Fuyuko FUKUYOSHI ${ }^{* *}$ \\ and Hiroyuki OGAWA ${ }^{* *}$ \\ ** Institute of Space and Astronautical Science, Japan Aerospace Exploration Agency \\ 3-1-1 Yoshinodai, Sagamihara, Kanagawa 229-8510, Japan \\ E-mail: hosei@isas.jaxa.jp \\ ***Department of Aerospace Engineering, Tohoku University, \\ 6-6-01, Aramaki-Aza-Aoba, Aoba-ku, Sendai 980-8579, Japan \\ E-mail: nagai.hiroki@aero.mech.tohoku.ac.jp
}

\begin{abstract}
This paper describes thermal performance of a small loop heat pipe device in an atmospheric condition. A comprehensive test program including start-up, power step up, power cycle and low power tests was performed. The effects of gravity on start-up and heat transport capability were also evaluated. An analytical model for the loop was developed to predict and evaluate the steady state operating performance. The test results demonstrated the robustness of the LHP. The analytical results showed good agreement with the test results except at the low power region. The feasibility of loop temperature control through compensation chamber temperature control was also experimentally demonstrated.
\end{abstract}

Key words: Loop Heat Pipe, Self Regulating, Spacecraft Thermal Control, Thermal Management, and Two-Phase Heat Transfer

\section{Introduction}

A loop heat pipe (LHP) is robust, self-starting and passive two-phase heat transfer devices, which utilize the latent heat vaporization of an internal working fluid to transfer heat, and the surface tension forces formed in a fine-porous wick to circulate the working fluid $^{(1,2)}$. Recently, LHPs are gaining increased acceptance for spacecraft thermal control as a next-generation standard heat transport device. LHPs are being used on several spacecrafts in USA, Russia, and other countries. In Japan, a few researches on the LHP have been reported. Ogushi et $\mathrm{al}^{(3)}$ developed a reservoir embedded LHP (RELHP), in which the reservoir is embodied in its wick core. The RELHP was installed in the Engineering Test Satellite (ETS-VIII) launched in 2006, and the performance was demonstrated in orbit. Another LHP is scheduled to be used in 2008 as part of the thermal control system of the Monitor of All-sky X-ray Image (MAXI), which is a first-generation payload for the Exposed Facility of the Japanese Experiment Module "Kibo" (JEM "Kibo"), part of the International Space Station (ISS) $)^{(4)}$.

The earlier LHP's were mainly designed for high-power applications on the order of 1 $\mathrm{kW}$. Current trends such as small satellites and interplanetary missions require the advancement of LHP technologies. One requirement is miniaturization of the LHPs for thermal control for small satellites and local control for subsystem. There are some investigations reported on miniature/small loop heat pipes and demonstrated 120-140 Wheat transport capability ${ }^{(5,6)}$. Another requirement is temperature control of the LHP. Some space applications such as optical sensors require the temperature to be maintained within a very narrow range. Interplanetary missions also require satisfying the thermal design in both high temperature and low temperature environment with limited energy resource. Temperature 
control of the loop is accomplished by controlling the compensation chamber (CC) temperature, and electrical heaters are usually used for CC active control. Recently, NASA Goddard Space Flight Center (GSFC) has conducted experimental investigations of using thermoelectric converters (TECs) for LHP temperature control ${ }^{(7)}$.

In this study, a $100 \mathrm{~W}$ class small LHP with tight temperature control function is investigated. This paper focuses on thermal performances of a small LHP based on a comprehensive test program in an atmospheric condition. At first, tests were conducted in a horizontal configuration to evaluate the basic performance of the LHP. The tests include start-up, power step up, power cycle and low power tests in an atmospheric condition. Next, the effects of gravity on thermal characteristics of the LHP were evaluated. The test was conducted by changing the orientation of the LHP against the gravity. An analytical model was also developed to predict and evaluate the steady state operating performance. Several test results in steady state were compared with the analytical results. Finally, the feasibility of loop temperature control through compensation chamber temperature control was evaluated.

\section{Nomenclature}

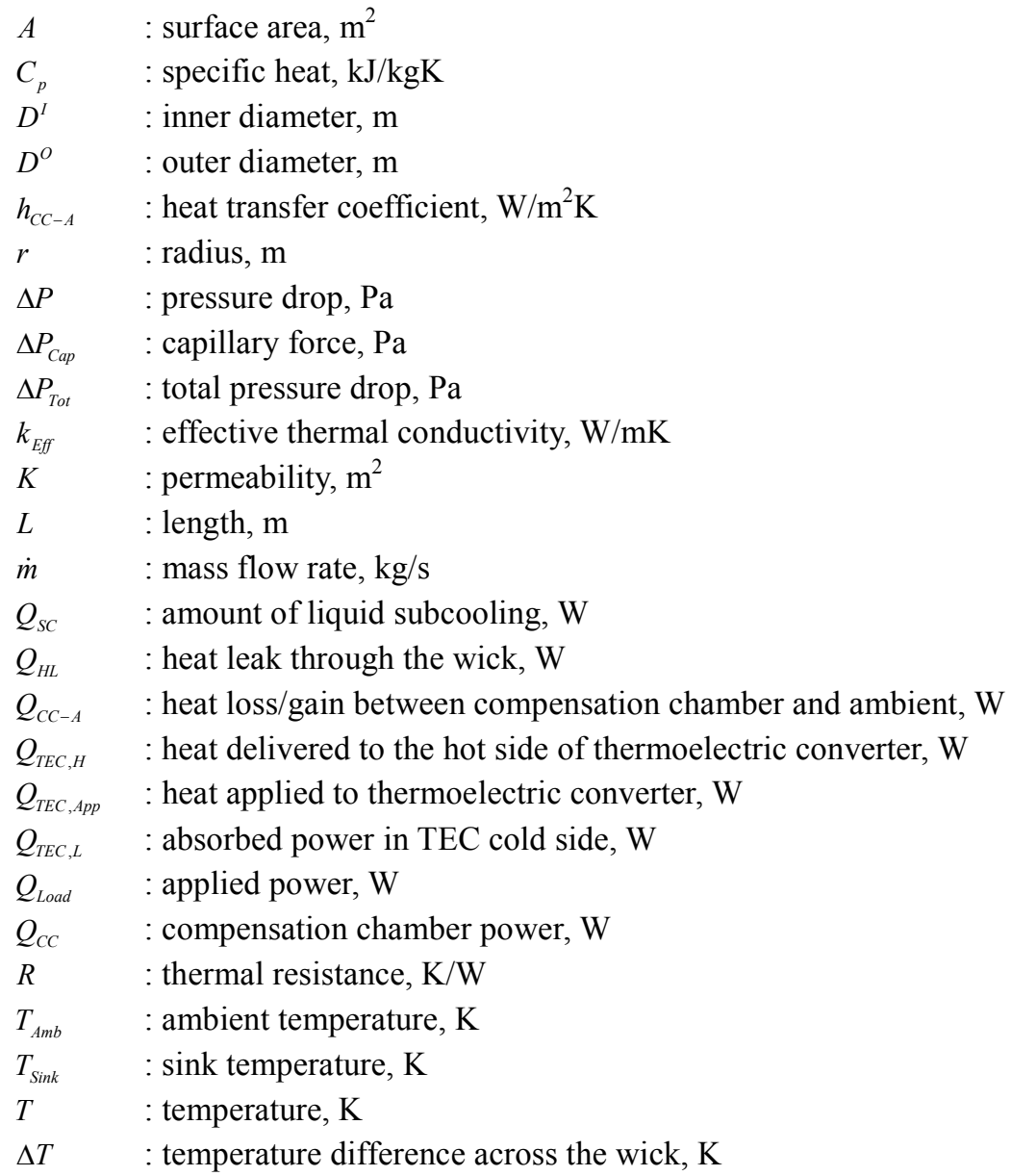

Greek symbols

$\begin{array}{ll}\theta & : \text { contact angle, }{ }^{\circ} \cdot \\ \sigma & : \text { surface tension, } \mathrm{N} / \mathrm{m} \\ \mu_{L} & : \text { viscosity of working fluid, } \mathrm{Pa} \cdot \mathrm{s} \\ \rho_{L} & : \text { density of working fluid, } \mathrm{kg} / \mathrm{m}^{3}\end{array}$




\section{Subscripts}

$\begin{array}{ll}\text { Evap } & \text { : evaporator } \\ \text { CC } & \text { : compensation chamber } \\ \text { Cond } & \text { : condenser } \\ \text { Vap } & \text { : vapor line } \\ \text { Liq } & \text { : liquid line } \\ \text { Wick } & \text { : wick } \\ \text { Groove } & \text { : groove } \\ \text { Grav } & \text { : gravity }\end{array}$

\section{Operating Principle of a LHP}

\subsection{Normal operation}

Figure 1 shows the schematic of a typical LHP. The LHP consists of an evaporator, a $\mathrm{CC}$, a vapor transport line, a condenser, and a liquid return line. A proper amount of the working fluid was charged in the LHP. Only the evaporator has a wick structure, and the rest of the loop components are made of smooth wall tubing. A normal operation of the LHP is explained as follows: Heat applied to the

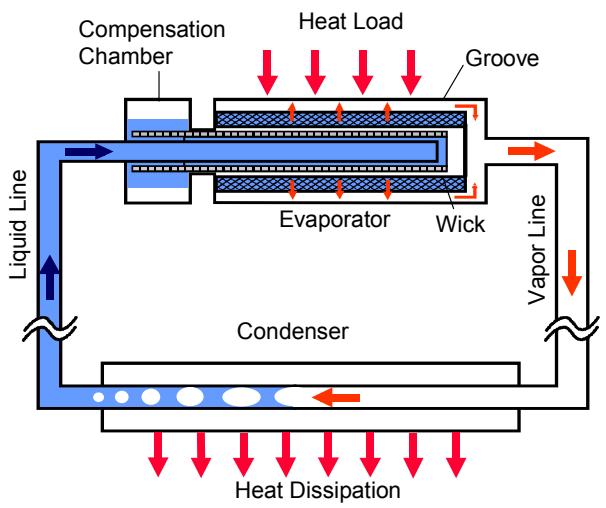

Fig. 1 Schematic of loop heat pipe evaporator vaporizes the liquid. The vapor generated in the evaporator is transported to the condenser through the vapor transport line. The vapor is condensed and subcooled in the condenser. The subcooled liquid is returned to the $\mathrm{CC}$ through the liquid return line. The $\mathrm{CC}$ stores the excess liquid. The $\mathrm{CC}$ controls the loop operating temperature since the fluid in the CC is always saturated. The detailed operation of the LHP is explained as follows: When the evaporator is heated, menisci are formed at vapor/liquid interfaces to develop the capillary pressure $\Delta P_{C a p}$ to transport the fluid around the loop, written as.

$$
\Delta P_{\text {Cap }}=\frac{2 \sigma \cos \theta}{r_{\text {Wick }}}
$$

where $\sigma$ is the surface tension of the working fluid, $r_{\text {wick }}$ is the effective pore radius of the wick, and $\theta$ is the contact angle between the liquid and solid. In order to operate the loop, it is necessary that the capillary pressure in the wick can sustain the total system pressure drop $\Delta P_{T o t}$, which is the sum of the pressure drops in the wick, vapor grooves, vapor line, condenser, liquid line, and the gravity head, i.e.

$$
\Delta P_{\text {Cap }} \geq \Delta P_{\text {Tot }}=\Delta P_{\text {Wick }}+\Delta P_{\text {Groove }}+\Delta P_{\text {Vap }}+\Delta P_{\text {Cond }}+\Delta P_{\text {Liq }}+\Delta P_{\text {Grav }}
$$

The pressure drop in the wick is

$$
\Delta P_{\text {Wick }}=\frac{\mu_{L}}{\rho_{L}} \frac{\ln \left(D_{\text {Wick }}^{o} / D_{\text {Wick }}^{I}\right)}{2 \pi L_{\text {Wick }} K} \dot{m}_{\text {Wick }}
$$

where $\mu_{L}$ and $\rho_{L}$ are the viscosity and the density of the fluid in liquid phase, $D_{\text {Wick }}^{o}$ and $D_{\text {Wick }}^{I}$ are the inner and outer diameter of the wick, $L_{\text {Wick }}$ and $K$ are the length and the 
permeability of the wick, and $\dot{m}_{\text {Wick }}$ is the mass flow rate across the wick.

Under steady state operational conditions, the energy balance of the LHP is as follows

$$
Q_{S C}=Q_{H L}-Q_{C C-A}
$$

where $Q_{S C}$ is the heat exchange between the $\mathrm{CC}$ and the returning liquid, $Q_{H L}$ is the conductive heat leak from the evaporator and the $\mathrm{CC}$ through the wick and the liquid core, and $Q_{C C-A}$ is the heat exchange between the $\mathrm{CC}$ and the ambient. The LHP operating temperature adjusts itself such that the condenser generates enough subcooling to match the heat leak and the heat exchange with the environment. $Q_{S C}$ is obtained by the following equation:

$$
Q_{S C}=\dot{m} C_{P}\left(T_{C C}-T_{I n}\right)
$$

where $\dot{m}$ and $C_{p}$ are the mass flow rate and the heat capacity of the fluid, $T_{C C}$ and $T_{I n}$ are the temperature of the $\mathrm{CC}$ and the inlet of the $\mathrm{CC}$, respectively. $Q_{H L}$ is obtained by the following equation:

$$
Q_{H L}=\frac{2 \pi k_{E f f} L_{\text {Wick }}}{\ln \left(D_{\text {Wick }}^{O} / D_{\text {Wick }}^{I}\right)}\left(T_{\text {Evap }}-T_{C C}\right)
$$

where $k_{E f f}$ is the effective thermal conductivity of the wick, $T_{E v a p}$ is the saturation temperature of the vapor inside the evaporator grooves, $T_{C C}$ is the saturation temperature of the fluid in the $\mathrm{CC}$. This temperature difference is caused by the total system pressure drop, excluding the pressure drop in the wick. This can be obtained from the Clausius-Clapeyron equation.

$$
T_{\text {Evap }}-T_{C C}=\left(\frac{\partial T}{\partial P}\right)_{\text {Sat }} \cdot\left(\Delta P_{\text {Total }}-\Delta P_{\text {Wick }}\right)
$$

The heat exchange between the $\mathrm{CC}$ and ambient can be written as,

$$
Q_{C C-A}=h_{C C-A} A_{C C}\left(T_{C C}-T_{A m b}\right)
$$

The CC temperature is determined by this energy balance.

\subsection{Temperature Control of LHP}

The loop operating temperature is determined by the saturation temperature of the two-phase working fluid in the CC. As discussed above, the saturation temperature in the $\mathrm{CC}$ is obtained by the energy balance written in eq. (4). Generally, the heat exchange between the CC and ambient $Q_{C C-A}$ is negligible and schematic thermal balance can be seen in Fig. 2(a). When the ambient temperature $T_{A m b}$ is higher than the sink temperature $T_{\text {Sink }}$, by which the condenser is surrounded, the CC temperature, which is natural operating temperature, draws a "V-shape" curve as a function of heat load $Q_{\text {Load }}$ as shown in Fig. 3. This tendency can be explained as follows ${ }^{(7)}$. At a low heat load, the liquid flow rate along the liquid line is small, resulting in a long residence time there. The liquid will be heated to approximately the ambient temperature due to a parasitic heat gain from ambient. Thus, the CC temperature will rise above the ambient temperature in order to satisfy the energy balance requirement. As the evaporator heat load increases, the mass flow rate increases and 
the residence time of the returning liquid in the liquid line decreases. This leads to a lower liquid temperature at the $\mathrm{CC}$ inlet and an increasing amount of liquid subcooling. The increase in the liquid subcooling more than compensates for the increase in the heat leak and leads to a decrease of the CC temperature. This trend continues until the condenser is fully utilized and the $\mathrm{CC}$ temperature reaches a minimum. Any increase in the evaporator heat load thereafter will result in warmer liquid flowing back to the $\mathrm{CC}$. The $\mathrm{CC}$ temperature will increase in order for the condenser to be able to dissipate the heat load.

When somewhat external thermal energy $Q_{C C}$ is actively applied to the CC, the energy balance in the $\mathrm{CC}$ is,

$$
Q_{C C}=Q_{S C}-Q_{H L}
$$

When an electrical heater is used for CC temperature control, applied heater power $Q_{\text {Heater }}$ corresponds to $Q_{C C}$. In this case, since the CC is only heated, the CC can be controlled when the eq. (10) is positive, that is to say, only when the natural operating temperature of the $\mathrm{CC}$ is lower than a set temperature (zone(2) in Fig. 3).

Figures 2(c) and (d) illustrate the idea of the CC temperature control by using a TEC module. One side of the TEC is attached to the CC and the other side is attached to the evaporator through a thermal strap. The TEC can both reject and absorb heat by changing the current flow from positive to negative. As a result, the $\mathrm{CC}$ can be both heated and cooled, and CC control area can be expanded up to zone (1) in Fig. 3. The required power for the CC heating using TEC will be lower than that using an electrical heater, since the TEC absorbs heat from the evaporator: The net thermal energy applied to the CC $Q_{C C}$ is the sum of the applied power to the TEC $Q_{T E C, A p p}$ and the absorbed energy in the TEC cold side $Q_{T E C, L}$.

$$
Q_{C C}=Q_{T E C, H}=Q_{T E C, A p p}+Q_{T E C, L}
$$

This means that the required power for the $\mathrm{CC}$ will be lower than the power when an electrical heater is used for the CC control. On the other hand, in zone (1) in Fig. 3, The CC is cooled by the TEC (Fig. 2(d)). In this case, the energy absorbed by the TEC from the CC supplies the evaporator side. As a result, the net power applied to the evaporator increases. 
Since the CC temperature decreases as the power applied increases, the required TEC power to cool the $\mathrm{CC}$ will decrease.

\section{Test Set-up and Conditions}

\subsection{Test Articles and Setup}

Figure 4 shows the schematic of the small LHP test article, which consists of an evaporator, a condenser, a vapor transport line and a liquid return line. The evaporator has a CC. About 11 grams of organic solvent was charged as a working fluid. Figure 5 shows a photograph of the small LHP. Table 1 lists the geometric parameters of the main components of the LHP. The evaporator was sandwiched by two aluminum blocks which simulate the instrument mass. A cartridge heater was attached to a thermal mass to provide heat loads between $1 \mathrm{~W}$ and 130W. A thermoelectric converter (TEC) was attached to the CC. A thermal strap, which was made of high thermal conductive graphite sheets, connected the rear side of the TEC to the evaporator. About thirty thermocouples were used to monitor the loop temperatures. A data acquisition system consisted of a data logger, a personal computer.

\subsection{Test Conditions}

Table 2 lists the test conditions. The tests were conducted to evaluate: (1) basic performance of the LHP, (2) gravity effects on operating behavior, and (3) feasibility of active temperature control of the LHP.

\section{(1) Basic performance test}

In order to evaluate the basic performance of the LHP, a test was conducted in a horizontal configuration without any active temperature control. At first, $10 \mathrm{~W}$ of power was applied to the evaporator for start up and then stepped up from $10 \mathrm{~W}$ to $120 \mathrm{~W}$ by $10-20 \mathrm{~W}$ increments. The next test was a power cycle test. $5 \mathrm{~W}$ was applied for start-up, and the power was increased up to $120 \mathrm{~W}$, and then the power was reduced down to $5 \mathrm{~W}$. This cycle was repeated twice. The third test was a low power test to demonstrate the low power operation of the LHP. The applied power to the evaporator was changed among $2 \mathrm{~W}$ to $5 \mathrm{~W}$.

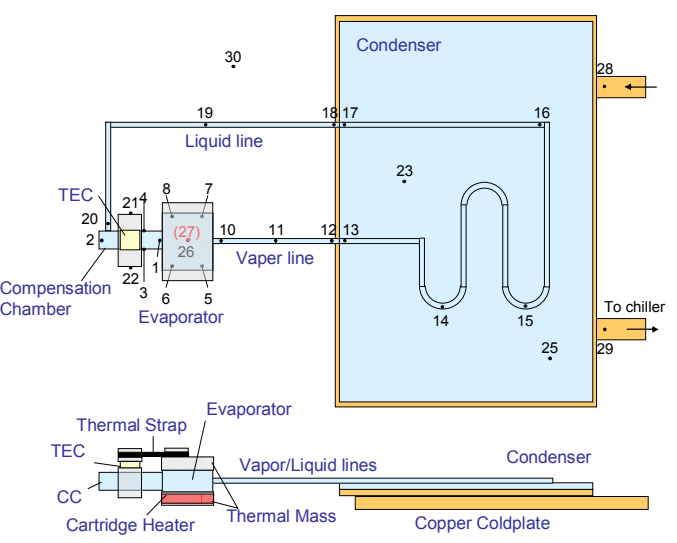

Fig. 4 Schematic of small LHP with thermocouple locations

Table 1. Small LHP design parameters

\begin{tabular}{|l|l|r|}
\hline \multicolumn{2}{|c|}{ Design Parameter } & \multicolumn{1}{c|}{ Value } \\
\hline \multirow{2}{*}{ Evaporator } & O. D. & $13.4 \mathrm{~mm}$ \\
\cline { 2 - 3 } & Length & $50.0 \mathrm{~mm}$ \\
\hline \multirow{4}{*}{ Wick } & O. D. & $13.0 \mathrm{~mm}$ \\
\cline { 2 - 3 } & Material & Nickel \\
\cline { 2 - 3 } & Pore Radius & $<6 \mu \mathrm{m}$ \\
\hline \multirow{3}{*}{ CC } & O. D. & $13.4 \mathrm{~mm}$ \\
\cline { 2 - 3 } & Length & $40.0 \mathrm{~mm}$ \\
\hline \multirow{3}{*}{ Liquid line } & O. D. & $4.0 \mathrm{~mm}$ \\
\cline { 2 - 3 } & Length & $100 \mathrm{~mm}$ \\
\cline { 2 - 3 } & Length & $4.0 \mathrm{~mm}$ \\
\hline \multirow{3}{*}{ Condenser } & O. D. & $233 \mathrm{~mm}$ \\
\cline { 2 - 3 } & Length & $4.0 \mathrm{~mm}$ \\
\cline { 2 - 3 } & Plate & $625 \mathrm{~mm}$ \\
\hline
\end{tabular}


Table 2 Test conditions

\begin{tabular}{|c|c|c|c|c|c|c|}
\hline & Sink & Tilt & $\begin{array}{c}\mathrm{CC} \\
\text { control }\end{array}$ & $\begin{array}{c}\text { Start } \\
\text { up }\end{array}$ & Test performed & No \\
\hline \multirow[t]{3}{*}{ Basic } & $5^{\circ} \mathrm{C}$ & $0^{\circ}$ & No & $10 \mathrm{~W}$ & Evap:10W/20W/40W/60W/80W/100W/120W & (1) \\
\hline & $5^{\circ} \mathrm{C}$ & $0^{\circ}$ & No & $5 \mathrm{~W}$ & Evap:5W/120W/5W/120W/5W & (2) \\
\hline & $0^{\circ} \mathrm{C}$ & $0^{\circ}$ & No & $2 \mathrm{~W}$ & Evap:2W/1W/5W/2W/1W & (3) \\
\hline \multirow[t]{3}{*}{$\begin{array}{l}\text { Gravity } \\
\text { effect }\end{array}$} & $\begin{array}{c}\mathrm{Amb} \\
\left(23^{\circ} \mathrm{C}\right)\end{array}$ & $0^{\circ}$ & No & $3 \mathrm{~W}$ & $\begin{array}{l}\text { Evap:3W/5W/7W/10W/15W/20W/25W/30W/35W/40W/ } \\
50 \mathrm{~W} / 60 \mathrm{~W} / 70 \mathrm{~W} / 80 \mathrm{~W} / 90 \mathrm{~W} / 100 \mathrm{~W} / 110 \mathrm{~W} / 120 \mathrm{~W} / 130 \mathrm{~W}\end{array}$ & (4) \\
\hline & $\begin{array}{c}\mathrm{Amb} \\
\left(23^{\circ} \mathrm{C}\right)\end{array}$ & $-90^{\circ}$ & No & $3 \mathrm{~W}$ & $\begin{array}{l}\text { Evap:3W/5W/7W/10W/15W/20W/25W/30W/35W/40W/ } \\
50 \mathrm{~W} / 60 \mathrm{~W} / 70 \mathrm{~W} / 100 \mathrm{~W} / 70 \mathrm{~W}\end{array}$ & (5) \\
\hline & $\begin{array}{c}\mathrm{Amb} \\
\left(23^{\circ} \mathrm{C}\right)\end{array}$ & $+90^{\circ}$ & No & $3 \mathrm{~W}$ & $\begin{array}{l}\text { Evap:3W/5W/7W/10W/15W/20W/25W/30W/35W/40W/ } \\
50 \mathrm{~W} / 60 \mathrm{~W} / 70 \mathrm{~W} / 100 \mathrm{~W} / 70 \mathrm{~W}\end{array}$ & (6) \\
\hline \multirow[t]{2}{*}{$\begin{array}{l}\text { Temp } \\
\text { control }\end{array}$} & $5^{\circ} \mathrm{C}$ & $0^{\circ}$ & $\mathrm{ON}$ & $10 \mathrm{~W}$ & $\begin{array}{l}\text { Evap: } 10 \mathrm{~W} / 20 \mathrm{~W} / 40 \mathrm{~W} / 60 \mathrm{~W} / 80 \mathrm{~W} / 100 \mathrm{~W} / 120 \mathrm{~W} \\
\text { CC: } 30^{\circ} \mathrm{C}\end{array}$ & (7) \\
\hline & $5^{\circ} \mathrm{C}$ & $0^{\circ}$ & ON & $50 \mathrm{~W}$ & $\begin{array}{l}\text { Evap: } 50 \mathrm{~W} \\
\text { CC: } 25^{\circ} \mathrm{C} / 30^{\circ} \mathrm{C} / 35^{\circ} \mathrm{C} / 40^{\circ} \mathrm{C} / 35^{\circ} \mathrm{C}\end{array}$ & (8) \\
\hline
\end{tabular}

\section{(2) Gravity effect}

The gravity effect on thermal performance was evaluated by changing the LHP orientation as shown in Fig. 6. In this test, the condenser was not actively cooled. That is, a coldplate to cool the condenser was not installed in order to change the orientation easily, and the heat exchange between the condenser and ambient is conducted by free convection. Note that the heat transfer coefficient for free convection on the condenser plate is dependent on its orientation, and it is difficult to make a quantitative comparison between horizontal and vertical orientations. This

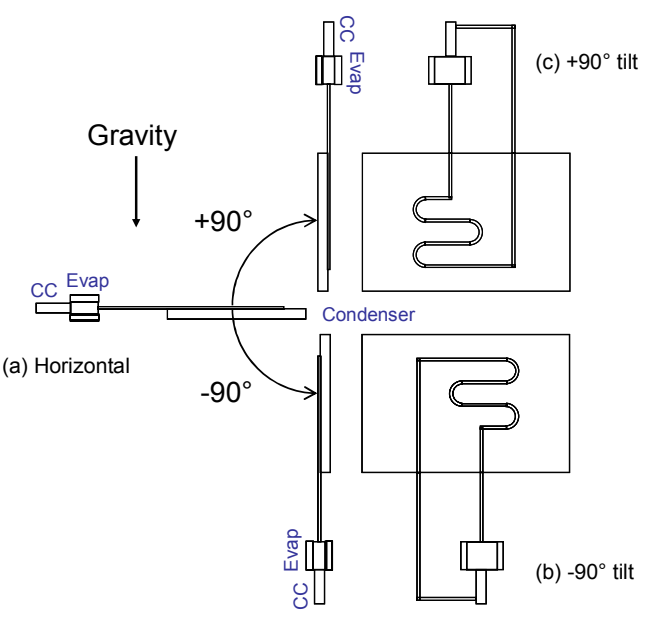

Fig. 6 Orientation of the LHP in gravity effect test test was conducted to investigate thermal-hydraulic behavior among the three orientations. At first, a test was conducted in a horizontal orientation as shown in Fig. 6(a). Applied power was stepped up from $3 \mathrm{~W}$ to $130 \mathrm{~W}$. Next, the test was conducted in which the evaporator was located above the CC, and the condenser was located above the evaporator as shown in Fig. 6(b). This condition seems favorable for the LHP operation since the liquid in the liquid line returns to the $\mathrm{CC}$ with the help of gravity, which makes the total pressure drop smaller. However, the $\mathrm{CC}$ which accumulates the liquid is located at the bottom of the evaporator, and this condition might cause insufficient liquid replenishment from the $\mathrm{CC}$ to the wick and/or a large heat leak from the evaporator to the $\mathrm{CC}$ across the wick. Finally, the test was conducted in which the evaporator was located below the $\mathrm{CC}$, and the condenser was located below the evaporator as shown in Fig. 6(c). The power was stepped up from $3 \mathrm{~W}$ to $100 \mathrm{~W}$. In this condition, the liquid in the liquid line transports against gravity and, as the result, the total pressure drop increases. On the other hand, the $\mathrm{CC}$ is located above the evaporator, and will provide enough liquid to the wick once the loop has started. 


\section{(3) Temperature control}

The temperature control test was conducted to demonstrate the feasibility of active control of the LHP operating temperature. The temperature control was conducted using a TEC module to control the CC temperature. Two kinds of tests were conducted. At first, the $\mathrm{CC}$ temperature was set at $40^{\circ} \mathrm{C}$ and power was increased from $10 \mathrm{~W}$ to $115 \mathrm{~W}$. Next, the power was fixed at $50 \mathrm{~W}$, and the $\mathrm{CC}$ temperature was controlled among $25^{\circ} \mathrm{C}$ to $40^{\circ} \mathrm{C}$.

\subsection{Analytical Conditions}

Based on the principle of the LHP described in the section 3.1, an analytical model in steady state was developed. In the model, the pressure drop in each component was calculated based on the Darcy's law, when the fluid in the component is in a single phase. In the part which contains two-phase, which is usually in the condenser, two-phase pressure drop was numerically calculated using the Lockhart-Martinelli model. Heat losses from the vapor line and liquid line and $\mathrm{CC}$ to the ambient were also taken into account. Thermal analysis was conducted based on the following assumptions;

(i) The wick is filled with liquid

(ii) The CC is filled with two-phase and has uniform temperature.

(iii) The loop is in steady state at given conditions.

(iv) Heat leak from the evaporator to the $\mathrm{CC}$ is only through the wick.

(v) Evaporator is uniformly heated.

Thermophysical properties of the fluid, such as specific heat, viscosity, density, thermal conductivity in both liquid and vapor phase, latent heat, surface tension, saturation pressure were obtained from equations as a function of the absolute temperature ${ }^{(8)}$.

The analysis was conducted in the following manner. At first, an arbitral saturation temperature of the evaporator side was decided. Local pressure drop and local temperature gain or loss were calculated. Saturation temperature in the $\mathrm{CC}$ was calculated from the eq. (7). Then, $Q_{H L}, Q_{C C-A}$, and $Q_{S C}$ were calculated. This flow was iteratively continued until eq. (4) was satisfied within $\pm 0.1^{\circ} \mathrm{C}$.

\section{Results and Discussions}

\subsection{Basic performance}

Figure 7 gives the temperature profile of the LHP's major parts in the step up test. When $10 \mathrm{~W}$ of power was applied, the loop started immediately as indicated by an increase of the vapor line temperature (TC11) up to saturation temperature. The loop temperature kept increasing until enough subcooled liquid came back to the $\mathrm{CC}$ to compensate for the leak from the evaporator to the CC. When the power applied increased to $20 \mathrm{~W}$, the overall temperature decreased because of the cold liquid returning from the condenser as explained in the section 3.2. This tendency continued until $60 \mathrm{~W}$ was applied. Above $60 \mathrm{~W}$, the overall temperature began to increase. The loop could be still operated stably when the power of $120 \mathrm{~W}$ was applied. The loop reached steady state within 30 minutes. When the power application to the evaporator was stopped, the loop stopped immediately. It can be confirmed that the vapor line

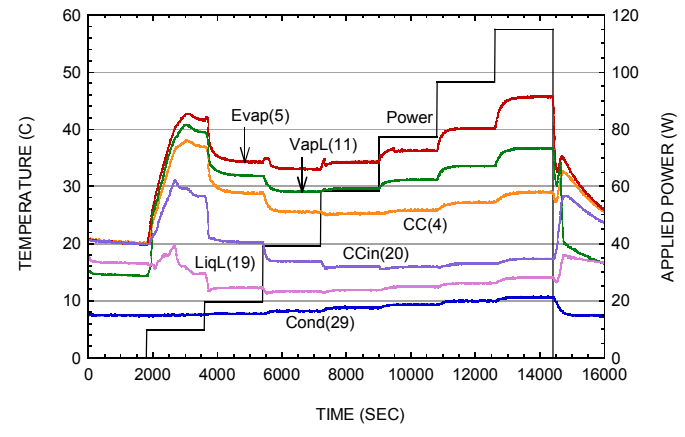

Fig. 7 Temperature profile in step-up test 


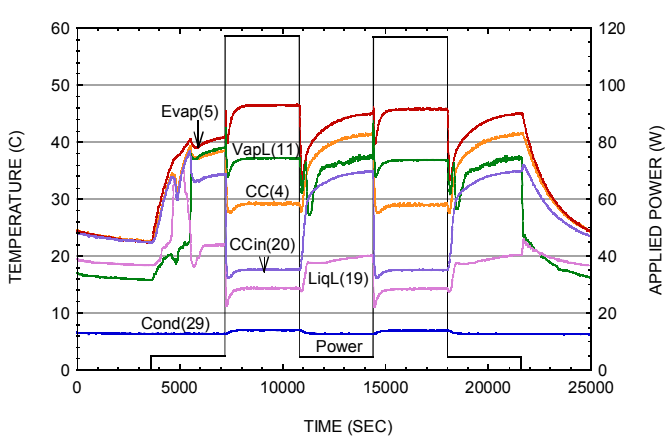

Fig.8 Temperature profile in power cycle test

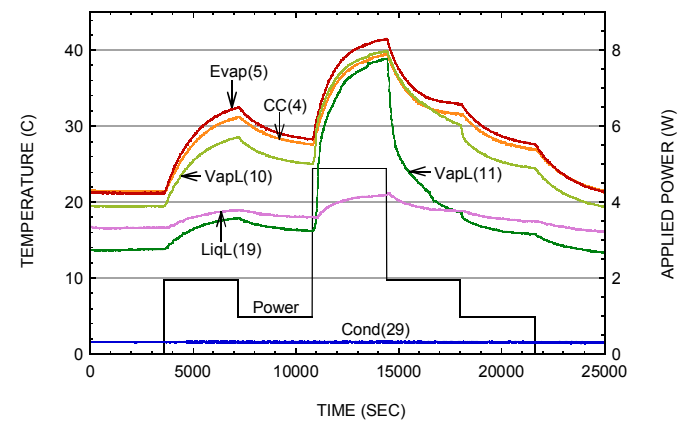

Fig. 9 Temperature profile in low power test

temperature suddenly dropped while the liquid temperature suddenly increased.

Figure 8 shows the temperature profile of the LHP in the power cycle test. When the power of $5 \mathrm{~W}$ was applied, the liquid line temperature increased up to saturation temperature for about 600 seconds, while the vapor line temperature did not increase. This means that the loop flowed in the reverse direction. It is considered that vaporization occurred in the inside of the wick before boiling started outside of the wick due to reasons unknown. This phenomenon could be seen in the several start-up tests. About 600 seconds after $5 \mathrm{~W}$ was applied, the vapor line temperature increase and the liquid line temperature dropped. This indicates that the loop started in the regular direction. When the power was increased to $120 \mathrm{~W}$, the loop responded quickly and reached steady state within $1000 \mathrm{sec}$. After that, the applied power was periodically changed between $5 \mathrm{~W}$ and $120 \mathrm{~W}$, and the loop responded quickly and adjusted its temperature. The loop stopped immediately after the power application was removed.

Figure 9 presents the temperature profile of the LHP in the low power test. When $2 \mathrm{~W}$ of power was applied to the evaporator for start-up, the overall temperature of the loop increased. The vapor line temperature also increased, but it did not reach to the saturation temperature. In this case, it is hard to tell whether the loop had started or not. There are two possibilities, one is that the loop did not start in such a low power, the other is that the loop did start and the condensation occurred in the vapor line instead of in the condenser. When the power was reduced to $1 \mathrm{~W}$, the overall temperature decreased. It is, however, also difficult to tell whether the loop was working or not. When the power was increased to $5 \mathrm{~W}$, the loop had clearly started since the vapor line temperature reached saturation temperature. After that, the power was reduced to $2 \mathrm{~W}$ again, the overall temperature decreased and the vapor line temperature clearly dropped. This means that there was liquid in the vapor line. When the power was reduced to $1 \mathrm{~W}$ again, the overall temperature decreased again. Temperature of TC10 and TC11 decreased at a higher rate than other temperatures. This means the cold liquid in the condenser was pulled back toward the evaporator side due to the power reduction. From this result, it could be considered that the LHP worked even at low power such as $1 \mathrm{~W}$.

\subsection{Gravity effect}

Figure 10 gives the temperature profile of the LHP in the step-up test in horizontal orientation. When $3 \mathrm{~W}$ of power was applied to the evaporator, the loop started immediately. Since the condenser was not actively cooled, that is, the sink temperature is equal to the ambient temperature, the loop temperature kept increasing as power increased. It was confirmed that the loop could operate even when the power of $130 \mathrm{~W}$ was applied without active cooling of the condenser.

Figure 11 shows the temperature profile of the LHP in the step-up test when the LHP set an $-90^{\circ}$ tilt as shown in Fig. 6(b). While the power applied to the evaporator was 


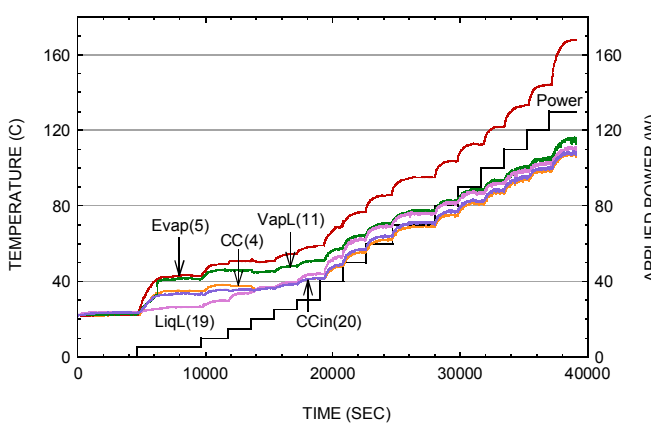

Fig. 10 Temperature profile in horizontal orientation

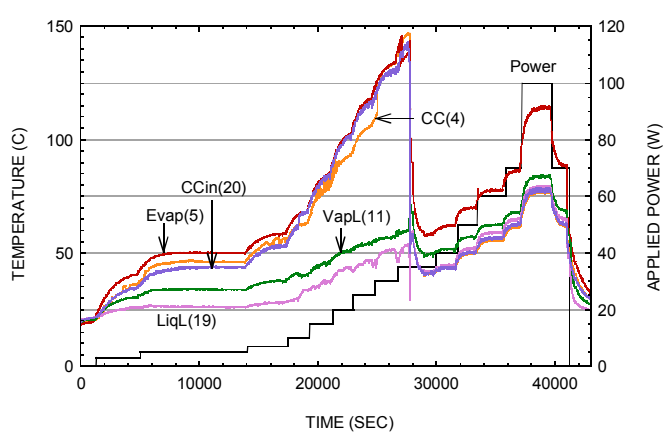

Fig. 12 Temperature profile in $+90^{\circ}$ tilt

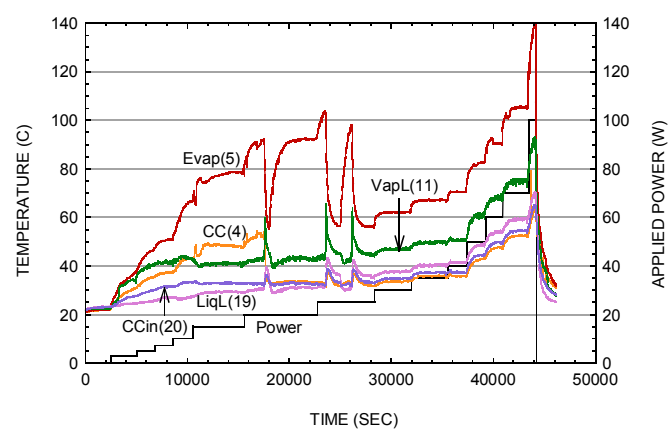

Fig. 11 Temperature profile in $-90^{\circ}$ tilt

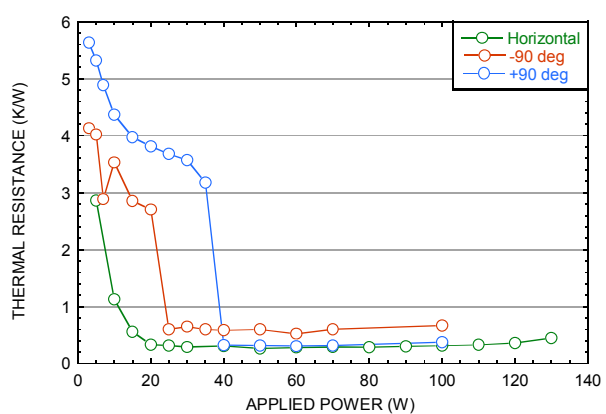

Fig. 13 Thermal resistance

between $3 \mathrm{~W}$ to $20 \mathrm{~W}$, the loop did not start as evident by the fact that the CC temperature showed higher than the vapor line temperature. When the power increased to $25 \mathrm{~W}$, the loop has started with short term temperature oscillation. It is considered that the condensed liquid in the condenser returned to the evaporator through the vapor line due to the gravity. Once the loop started, it operated stably until $70 \mathrm{~W}$ of power was applied. When the power increased to $100 \mathrm{~W}$ from $70 \mathrm{~W}$, the loop temperature suddenly increased. The loop might have been dried-out at this point.

Figure 12 presents the temperature profile of the LHP in the step-up test when the LHP set an $+90^{\circ}$ tilt as shown in Fig. 6(c). While the power applied to the evaporator was between $3 \mathrm{~W}$ to $30 \mathrm{~W}$, the loop did not start. The evaporator temperature exceeded $130^{\circ} \mathrm{C}$ when the power of $30 \mathrm{~W}$ was applied, and the $\mathrm{CC}$ temperature also rose with the evaporator temperature. It is considered that the wick core was not filled with liquid in the initial condition, and consequently, heat leak from the evaporator to the CC became large. When the power increased to $35 \mathrm{~W}$, the loop started, and the overall temperature dropped. After the loop started, it showed more stable operation than that in $-90^{\circ}$ tilt in Fig. 11 since any temperature oscillation did not arise. The loop could be operated when the $100 \mathrm{~W}$ was applied. The operating temperature of the loop was lower than that in $-90^{\circ}$ tilt.

Figure 13 shows thermal resistance as a function of applied power in the three orientations. The thermal resistance $R$ is defined as,

$$
R=\frac{T_{\text {Evap }}-T_{\text {Cond }}}{Q_{\text {Load }}}
$$

where $T_{\text {Evap }}$ and $T_{\text {Cond }}$ are the evaporator and condenser temperatures.

In the horizontal orientation, the thermal resistance decreased as power increased from 
$3 \mathrm{~W}$ to $20 \mathrm{~W}$ and reached almost constant above $20 \mathrm{~W}$. In the $-90^{\circ}$ orientation, the thermal resistance below 20W was very high because the loop did not start. Once the loop started, however, the thermal resistance reached almost constant. In $+90^{\circ}$ orientation, similar phenomenon was confirmed. That is to say, the thermal resistance below $40 \mathrm{~W}$ was very high since the loop did not operate. Once the loop operated above $40 \mathrm{~W}$, the thermal resistance was constant. Since the heat transfer coefficient for free convection on the condenser plate is different between horizontal and vertical orientations, it is difficult to compare the performance by the value of the thermal resistance between these orientations. Hereafter, the thermal resistances between the two vertical orientations $\left( \pm 90^{\circ}\right)$ are compared. The thermal resistance in $-90^{\circ}$ tilt was higher than that in $+90^{\circ}$ tilt after the loop had started. This is because the evaporator temperature in $-90^{\circ}$ tilt was about 10 to $20^{\circ} \mathrm{C}$ higher than that in $+90^{\circ}$ tilt while the condenser temperatures were almost the same. A main reason given for this temperature difference is that in $-90^{\circ}$ tilt, the heat leak became large since the liquid was accumulated at the bottom of the CC, whereas in $+90^{\circ}$ tilt, the liquid accumulated at the wick core. A more reliable liquid transport from the $\mathrm{CC}$ to the wick could be accomplished in $+90^{\circ}$ tilt with the help of gravity.

\subsection{Analytical result in steady state}

Figure 14 gives the comparison of the loop operating temperature between test results and analytical results in steady state. They agreed well within $\pm 3^{\circ} \mathrm{C}$ at higher power region above $40 \mathrm{~W}$, while they showed different temperatures at low power operation below 20W. The following reasons can be considered to explain such discrepancies at low power region.

(i) Heat exchange between the $\mathrm{CC}$ and the ambient was not calculated correctly.

(ii) Phase conditions in the wick were different between the test and analysis.

The heat exchange with ambient is more pronounced at low powers, while the energy balance is dominated by the liquid returning from the condenser at high powers. Kaya et al and Bienert et al also report less accuracy at low powers in operating temperature predictions due to the difficulty in modeling the heat exchange ${ }^{(9,10)}$. In addition to that, phase conditions in the wick might also affect the accuracy of the modeling. At low power application, almost all liquid will go out of the CC and exist in the loop components except the CC. In the CC, a little amount of liquid will remained. If the amount of the liquid charged in the LHP is insufficient, the assumption (ii) and (iii) in the section 4.3 cannot be satisfied. And, as a result, the heat leak will be larger than the assumption. Since several test results also indicates an under-charge phenomenon such as reverse flow in start-up, as shown in Fig. 8, it is considered that under-charge of the working fluid in the LHP might relate to the discrepancy at low power region.

\subsection{Temperature control}

Figure 15 shows the temperature profile of the LHP in the step-up test when the CC was actively controlled. The CC temperature was set at $30^{\circ} \mathrm{C}$. It was confirmed that the $\mathrm{CC}$ temperature, that is, the loop operating temperature can be controlled at a constant. Since 


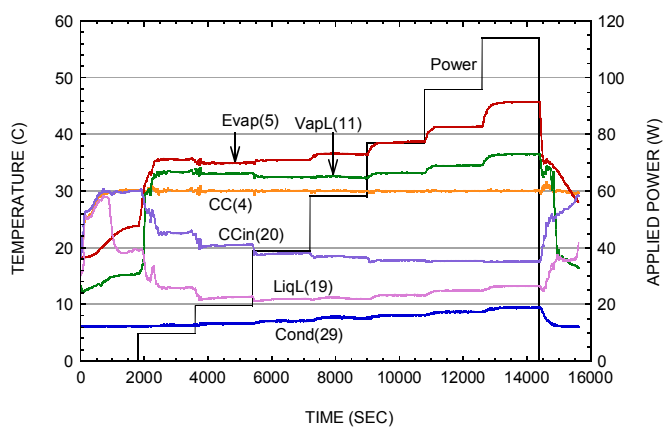

Fig. 15 CC Temperature Profile

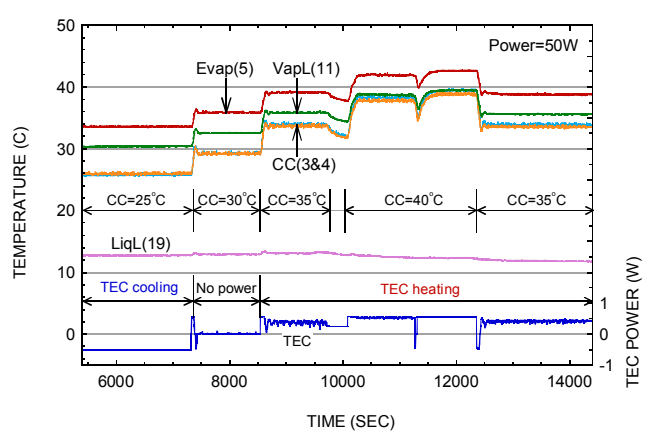

Fig. 16 LHP Temperature Profile at a Constant Power

the natural operating temperature at $10 \mathrm{~W}$ power apply to the evaporator when the $\mathrm{CC}$ was not controlled is above $35^{\circ} \mathrm{C}$ as shown in Fig. 7 (Test No. 1), the CC was cooled by the TEC module at $10 \mathrm{~W}$ power apply. Above $20 \mathrm{~W}$, the CC was heated by the TEC module.

Figure 16 presents the overall temperature and the required TEC power when the $\mathrm{CC}$ temperature was controlled from $25^{\circ} \mathrm{C} / 30^{\circ} \mathrm{C} / 35^{\circ} \mathrm{C} / 40^{\circ} \mathrm{C}$ when the power of $50 \mathrm{~W}$ was applied to the evaporator. It was demonstrated that the loop operating temperature can be controlled at desired temperature, although the $\mathrm{CC}$ could not reach $40^{\circ} \mathrm{C}$ due to the limited capabilities of the power supply. In addition to that, the $\mathrm{CC}$ can be controlled below the natural operating temperature (about $30^{\circ} \mathrm{C}$ ) by cooling the $\mathrm{CC}$ with the TEC. This is the great potential in using the TEC module.

\section{Conclusions}

In order to evaluate the thermal performance of a small loop heat pipe, a comprehensive test program was executed. An analytical model for the small LHP was also developed. Results are summarized as follows:

(i) A basic performance test demonstrated the robust operation of this loop among $5 \mathrm{~W}$ to $120 \mathrm{~W}$ in horizontal orientation. The possibility of the loop operating below $5 \mathrm{~W}$ was also demonstrated.

(ii) The test was conducted in the different orientation of the loop, and the effects of the gravity on thermal behavior were evaluated. The results indicate that once loop started, loop operates stably and showed the constant thermal resistance regardless of orientation.

(iii) Analytical model of the LHP was developed, and analytical results agreed well with the test results within $3^{\circ} \mathrm{C}$ except for the low power operation.

(iv) The loop operating temperature can be actively controlled through the CC temperature control with a small amount of power. By using a TEC module, the loop operating temperature can be controlled both higher and lower than the natural operating temperature.

\section{Acknowledgement}

The primary author would like to thank to Dr. Jentung Ku of NASA Goddard Space Flight Center for advice in this research and is also grateful to the JSPS Postdoctoral Fellowships for Research Abroad. 


\section{References}

(1) J. Ku, "Operating Characteristics of Loop Heat Pipes," The 29th International Conference on Environmental Systems, SAE Paper No. 1999-01-2007, (1999).

(2) Y. F. Maidanik, Y. G. Fershtater, and N. N. Solodovnik, "Loop Heat Pipes: Design, Investigation, Prospects of Use in Aerospace Technics," SAE Paper No 1994-1185, (1994).

(3) T. Ogushi, A. Yao, H. Ishikawa, S. Haga, A. Miyasaka, and H. Noda, "Mathematical Modeling for Predicting Steady State and Transient Characteristics of Reservoir Embedded Looped Heat Pipe (RELHP)," The 31st International Conference on Environmental Systems, SAE Paper No. 2001-01-2239 (2001).

(4) H. Nagai, and S. Ueno, "Performance Evaluation of Doublecondenser Loop Heat Pipe onboard Monitor of All-sky X-ray Image (MAXI) in Thermal Vacuum Testing," The 35th International Conference on Environmental Systems, SAE Paper No. 2005-01-2939 (2005).

(5) J. Ku, "Testing of a Miniature Loop Heat Pipe Using a Thermal Electrical Cooler for Temperature Control," The 34th International Conference on Environmental Systems, SAE Paper No. 2004-01-2505 (2004).

(6) M. Pauken, "Thermal Performance Evaluation of a Small Loop Heat Pipe for Space Applications The 33rd International Conference on Environmental Systems," SAE Paper No. 2003-01-2688 (2003).

(7) J. Ku and H. Nagano, "Loop Heat Pipe Operation with Thermoelectric Converters and Coupling Blocks," 5th International Energy Conversion Engineering Conference and Exhibit, AIAA 2007-4713 (2007).

(8) P. J. Brennan, and E. J. Kroliczek, "Heat Pipe Design Handbook," NASA Contract NAS5-32406, Vol.2, MD, June pp. 62-67, (1979).

(9) T. Kaya, and T. T. Hoang, "Mathematical model Mathematical Modeling of Loop Heat Pipes and Experimental Validation," Journal of Thermophysics and Heat Transfer, Vol. 13, No. 3, pp. 314-320 (1999).

(10) W. B. Bienert, and D. A. Wolf, "Temperature Control with Loop Heat Pipes: Analytical Model and Test Results," Proceedings of the 9th International Heat Pipe Conference, Los Alamos National Laboratory, (1995). 